\title{
Identification of Leptospira species of Korean Isolates using Phylogenetic Analysis of Polymerase Chain Reaction-amplified 16S rDNA and LipL32 Genes
}

\author{
Kyung-Hee Park ${ }^{1}$, Yeon-Joo Choi ${ }^{1,2}$, Sun-Hye Shin ${ }^{1}$, Min-Kyung Choi ${ }^{1}$, \\ Yoon-Won $\mathrm{Kim}^{3}$ and Won-Jong Jang ${ }^{1,2^{*}}$ \\ ${ }^{I}$ Department of Microbiology and ${ }^{2}$ Institute of Glocal Disease Control, College of Medicine, Konkuk University, Seoul; \\ ${ }^{3}$ Department of Microbiology, College of Medicine, Hallym University, Chunchon, Kangwon-do, Korea
}

In this study, we selected only serologically identified 15 Leptosira interrogans isolates in the past and analyzed and identified them by using molecular method. The partial 16S rDNA and LipL32 genes were amplified from the bacteria by polymerase chain reaction (PCR) and sequenced. Sizes of the PCR products were 529 bp and 819 bp respectively and analysis of the nucleotide sequence of 16S rDNA and LipL32 genes showed that 14 out the 15 Leptospira showed $99.4 \sim 100 \%$ and $99.2 \sim 99.9 \%$ similarity respectively to those of $L$. interrogans lai and one isolate named HS-7 showed $100 \%$ and $100 \%$ similarity to $L$. interrogans canicola. The phylogenetic tree based on the $16 \mathrm{~S}$ rDNA and LipL32 genes obtained the study revealed that 14 of the Leptospira composed a cluster distinct to that of L. interrogans lai and HS- 7 composed to L. interrogans canicola.

Key Words: Leptospira interrogans, Serovar, Genospecies

\section{INTRODUCTION}

렙토스피라증(Leptospirosis)은 전세계적으로 발생하는 인수공통질환으로 렙토스피라(genus Leptospira)에 속하는 병원성 균에 의해 일어난다 (1). 1989년 이전, 렙토스피 라는 혈청학적 분류에 따라 모든 병원성균을 포함하는 Leptospira interrogans sensu lato와 비병원성균을 포함하 는 L. biflexa sensu lato 두 그룹으로 나뉘었다 (2). $L$. interrogans 는 혈청학적인 방법으로 23 혈청군(serogroup) 과 223여 개의 혈청형(serovar)으로 구분되고, 유전학적 분류방법에 따라서는 13 종의 병원성 균과 6 종의 비병원 성 균을 포함하여 최소 약 19종으로 나눠진다고 보고되
었다 (2 5). 1984년에 국내에서도 렙토스피라증이 발생 되고 있음이 증명되었고, L. interrogans Icterohemorrhagiae 혈청군(serogroup)에 속하는 균이 원인균으로 분리동정 되었다 (6). 국내에서 분리되는 렙토스피라 균주는 주로 Icterohemorrhagiae 혈청군에 속하는 lai 혈청형이고, 새 로운 hongchon과 yeonchon 혈청형이 결정된 바 있으며, Canicola 혈청군에 속하는 canicola 혈청형도 환자로부터 분리되었다 $(3,7)$. 렙토스피라균을 동정하는 방법은 응집 (agglutination)에 의한 혈청학적 분류방법이 기본적인 방 법이다. 혈청학적인 동정방법으로는 전통적인 방법인 교 차응집소 흡수시험법(cross-absorption agglutination test) 과 비교적 빠른 동정방법인 현미경응집검사(microscopic agglutination test)가 있다 (7). 혈청군은 현미경응집검사로

Received: December 28, 2013/ Revised: February 10, 2014/ Accepted: February 28, 2014

*Corresponding author: Won-Jong Jang. Department of Microbiology, College of Medicine, Konkuk University, 120 Neungdong-ro, Gwangiin-gu, Seoul, 143-701, Korea.

Phone: +82-2-2030-7816, Fax: +82-2-2030-7845, e-mail: wjjang@kku.ac.kr

** This work was supported by the Konkuk University.

(c) This is an Open Access article distributed under the terms of the Creative Commons Attribution Non-Commercial License (http://creativecommons.org/license/by-nc/3.0/) 
결정할 수 있고, 혈청형은 교차응집소 흡수시험법에 의해 결정된다 (8). 그러나 이들 방법은 수적인 제약과 시간이 많이 걸리는 단점이 있다. 이 후 단세포군항체를 이용한 혈청학적인 동정방법이 시도되었고 (9), 최근 분리 균 주의 동정방법의 대안으로 DNA를 기초로 한 분자생물 학적 분류기법이 개발되어 왔다. 분자생물학적 분류방법 에는 DNA-DNA hybridization을 비롯하여 pulsed field gel electrophoresis (PFGE), restriction fragment length polymorphism (RFLP), rrs sequencing, 그리고 특정 유전자에 대한 sequencing 등의 다양한 기법들이 있고, 이들 DNA 를 바탕으로 하는 렙토스피라의 재분류는 분류학적으로 비교적 정확하여 분류에 강한 기반을 제공한다 $(6,10$ 13). Polymerase chain reaction (PCR)은 임상증세를 보인 환 자의 검체로부터 렙토스피라를 빠르고 민감하게 검출하 는 데 유용한 분자생물학적인 방법 중 하나이다 (14). 또 한 이를 통해 렙토스피라의 병원성과 비병원성을 구분할 수 있다 (15). PCR을 이용한 렙토스피라 검출 및 종 동정 에 사용하는 유전자들은 일반적으로 렙토스피라 뿐만 아 니라 리케차를 포함하여 여러 세균의 동정에 사용되는 $16 \mathrm{~S} \mathrm{rDNA}$ 유전자와 병원성 렙토스피라의 면역반응에서 주요한 항원으로 알려진 OmpL1, LipL32, LipL36, LipL41 그리고 LipL48 등의 외막단백(outer membrane protein) 유 전자가 있다 $(11,15 \sim 18)$. 균주의 동정을 정확하게 하는 것은 렙토스피라증의 역학조사와 병인연구에 중요할 뿐 만 아니라 진단법 및 백신개발을 위한 기초자료를 제공 할 수 있으므로 질병예방에 큰 도움이 된다. 국내 분리 균주들은 앞서 기술한 바와 같이 주로 혈청학적인 방법 으로 분류가 되었으며, 일부 DNA 분석을 통한 분류가 시도된 바 있다 (7). 따라서 본 연구에서는 기존의 방법 으로 분류되었던 국내 분리 균주들의 특성 분석에 보다 많은 정보를 추가하기 위하여 $16 \mathrm{~S} \mathrm{rDNA}$ 와 LipL32 유전 자 일부분의 염기서열 분석을 실시하고자 하였다.

\section{MATERIALS AND METHODS}

\section{사용 균주}

본 실험에서 사용한 균주는 Table 1과 같다. 렙토스피 라 균주 중 일부는 서울대학교 의과대학 미생물학교실과 한림대학교 의과대학 미생물학교실에서 분양받았으며, 일 부는 건국대학교에서 환자 및 야생 설치류에서 분리한 균주를 사용하였다. 이 중 1984년부터 1990년 사이에 국
Table 1. Local Leptospira strains isolated in Korea for molecular typing using nucleotide sequences of 16S rDNA and LipL32 genes

\begin{tabular}{llll}
\hline \hline Strain & \multicolumn{1}{c}{ Source } & $\begin{array}{l}\text { Area of } \\
\text { isolation }\end{array}$ & Year \\
\hline WH-20 & Human & Wonju & 1984 \\
18R & Wild rodent & Hongchon & 1985 \\
30R & Wild rodent & Hongchon & 1985 \\
HS-7 & Human & Kongju & 1985 \\
HM3 & Human & Yeonchun & 1985 \\
AP33 & Rat & Yeoju & 1987 \\
CH88-12 & Human & Choonsung & 1988 \\
CH88-19 & Human & Whachun & 1988 \\
KH-1 & Human & Choongju & 1989 \\
KH-2 & Human & Choongju & 1989 \\
HK-12 & Human & Kosung & 1990 \\
A-15 & Apodemus agrarius & Choongju & 1993 \\
A-19 & Apodemus agrarius & Choongju & 1993 \\
M06 & Apodemus agrarius & Choongju & 2001 \\
M07 & Apodemus agrarius & Choongju & 2001 \\
\hline & & & \\
\hline
\end{tabular}

내에서 발생한 환자 및 포획 야생쥐로부터 분리한 균 주 중 동정이 어려웠던 7주의 렙토스피라 균주가 포함되 었다.

\section{렙토스피라 분리균의 배양}

렙토스피라균의 배양에는 Ellinghausen-McCulloughJohnson-Harris (EMJH) 배지를 사용하였다. 일반적인 배 양은 액체 $\mathrm{EMJH}$ 배지로 $32^{\circ} \mathrm{C}$ 에서 7 10일 간격으로 배 양하고, 균주를 보관하기 위해서는 반고체 $\mathrm{EMJH}$ 배지 $(0.2 \%$ agar 포함)에 배양하였다.

\section{렙토스피라균주 DNA 추출 및 증폭}

렙토스피라로부터 핵산을 추출하기 위하여 QIAamp DNA mini kits (QIAamp DNA mini kit; Qiagen Valencia, CA, USA)를 사용하였으며, 제조사에 방법에 따라 핵산을 추 출하였다. 추출한 렙토스피라 핵산으로부터 특정 유전자 를 증폭하기 위해 $16 \mathrm{~S} \mathrm{rDNA}$ 와 LipL32 유전자를 타겟으 로 하는 프라이머를 이용하여 $\mathrm{PCR}$ 을 실시하였다 (Table 2) (12, 19 21). PCR 반응 혼합물은 Template DNA $2 \mu \mathrm{l}$ 에 
$2.5 \mathrm{mM}$ dNTP $4 \mu \mathrm{l}$ (Bioline, UK), $10 \times$ PCR buffer $5 \mu \mathrm{l}$ (Bioline, UK)와 0.25 U Taq polymerase (Bioline, UK)를 넣고 각각 $20 \mathrm{pmol} / \mu \mathrm{l}$ 프라이머 $1 \mu \mathrm{l}$ 씩을 넣은 후, 멸균증류수 를 넣어 총 $50 \mu \mathrm{l}$ 로 최종부피를 맞췄다. PCR은 GeneAmp PCR system 9600 (Perkin Elmer Applied Biosystems, Foster
City, Calif, USA)로 실행하였으며, PCR 조건에서 $16 \mathrm{~S}$ $\mathrm{rDNA}$ 는 $94^{\circ} \mathrm{C}$ 에서 5 분간 변성시킨 후 $94^{\circ} \mathrm{C}$ 에서 30 초간 denaturation, $55^{\circ} \mathrm{C}$ 에서 30 초간 annealing, $72^{\circ} \mathrm{C}$ 에서 1 분 30 초간 extension순으로 35 회 증폭시켰으며, 최후 반응 $72^{\circ} \mathrm{C}$ 에서 3 분간 반응시켜 $\mathrm{PCR}$ 산물의 연장을 유도하였

Table 2. Nucleotide sequences of primers and conditions for PCR used in this study

\begin{tabular}{|c|c|c|c|}
\hline Target genes & Primer & Nucleotide sequence $\left(5^{\prime} \rightarrow 3^{\prime}\right)$ & Products size (bp) \\
\hline \multirow{2}{*}{$16 S r D N A$} & $27 \mathrm{~F}^{\mathrm{a}}$ & AGAGTTTGATCMTGGCTCAG & \multirow{2}{*}{529} \\
\hline & $518 \mathrm{R}^{\mathrm{a}, \mathrm{b}}$ & GTATTACCGCGGCTGCTGG & \\
\hline \multirow{2}{*}{ lipL32 } & LipL32F ${ }^{\mathrm{a}}$ & ATGAAAAAACTTTCGATTTTG & \multirow{2}{*}{819} \\
\hline & $\operatorname{LipL32R^{a,b}}$ & TTACTTAGTCGCGTCAGAAGC & \\
\hline
\end{tabular}

${ }^{\mathrm{a}}$ Primers used for amplification and sequencing, ${ }^{\mathrm{b}}$ reverse primers

Table 3. The similarity between partial $16 \mathrm{SrDNA}$ sequences of various reference Leptospira strains and isolates

\begin{tabular}{|c|c|c|c|c|c|c|c|c|c|c|c|c|c|c|c|c|c|c|c|}
\hline & 1 & 2 & 3 & 4 & 5 & 6 & 7 & 8 & 9 & 10 & 11 & 12 & 13 & 14 & 15 & 16 & 17 & 18 & 19 \\
\hline 1 & $* * *$ & 100 & 100 & 100 & 100 & 100 & 99.7 & 97.8 & 97.8 & 99.7 & 98.5 & 97.2 & 97.8 & 97.8 & 99.4 & 99.7 & 99.7 & 100 & 99.7 \\
\hline 2 & & $* * *$ & 100 & 100 & 100 & 100 & 99.7 & 97.8 & 97.8 & 99.7 & 98.5 & 97.2 & 97.8 & 97.8 & 99.4 & 99.7 & 99.7 & 100 & 99.7 \\
\hline 3 & & & $* * *$ & 100 & 100 & 100 & 99.7 & 97.8 & 97.8 & 99.7 & 98.5 & 97.2 & 97.8 & 97.8 & 99.4 & 99.7 & 99.7 & 100 & 99.7 \\
\hline 4 & & & & $* * *$ & 100 & 100 & 99.7 & 97.8 & 97.8 & 99.7 & 98.5 & 97.2 & 97.8 & 97.8 & 99.4 & 99.7 & 99.7 & 100 & 99.7 \\
\hline 5 & & & & & $* * *$ & 100 & 99.7 & 97.8 & 97.8 & 99.7 & 98.5 & 97.2 & 97.8 & 97.8 & 99.4 & 99.7 & 99.7 & 100 & 99.7 \\
\hline 6 & & & & & & $* * *$ & 99.7 & 97.8 & 97.8 & 99.7 & 98.5 & 97.2 & 97.8 & 97.8 & 99.4 & 99.7 & 99.7 & 100 & 99.7 \\
\hline 7 & & & & & & & $* * *$ & 97.5 & 97.5 & 99.4 & 98.1 & 96.9 & 97.5 & 97.5 & 99.1 & 99.4 & 99.4 & 99.7 & 100 \\
\hline 8 & & & & & & & & $* * *$ & 96.9 & 98.1 & 97.5 & 97.2 & 98.8 & 99.1 & 97.2 & 97.5 & 97.5 & 97.8 & 97.5 \\
\hline 9 & & & & & & & & & $* * *$ & 98.1 & 98.8 & 96.9 & 96.9 & 97.5 & 97.2 & 97.5 & 97.5 & 97.8 & 97.5 \\
\hline 10 & & & & & & & & & & $* * *$ & 98.8 & 97.5 & 98.1 & 98.1 & 99.1 & 99.4 & 99.4 & 99.7 & 99.4 \\
\hline 11 & & & & & & & & & & & $* * *$ & 97.8 & 97.5 & 98.1 & 97.8 & 98.1 & 98.1 & 98.5 & 98.1 \\
\hline 12 & & & & & & & & & & & & $* * *$ & 96.6 & 97.5 & 96.6 & 96.9 & 96.9 & 97.2 & 96.9 \\
\hline 13 & & & & & & & & & & & & & $* * *$ & 99.1 & 97.2 & 97.5 & 97.5 & 97.8 & 97.5 \\
\hline 14 & & & & & & & & & & & & & & $* * *$ & 97.2 & 97.5 & 97.5 & 97.8 & 97.5 \\
\hline 15 & & & & & & & & & & & & & & & $* * *$ & 99.1 & 99.1 & 99.4 & 99.1 \\
\hline 16 & & & & & & & & & & & & & & & & $* * *$ & 99.4 & 99.7 & 99.4 \\
\hline 17 & & & & & & & & & & & & & & & & & $* * *$ & 99.7 & 99.4 \\
\hline 18 & & & & & & & & & & & & & & & & & & $* * *$ & 99.7 \\
\hline 19 & & & & & & & & & & & & & & & & & & & $* * *$ \\
\hline
\end{tabular}

1, partial 16S rDNA of L. interrogans Lai 56601 (NR074481); 2, L. interrogans Coppenhageni (JQ988857); 3, L. interrogans Autumnalis Akiyami A (FJ154557); 4, L. Interrogans Icterohaemorrhagiae RGA(FJ154549); 5, L. interrogans Kremastos (FJ154564); 6, L. interrogans Medanesis (DQ991471); 7, L. interrogans Canicola DB34 (JQ988855); 8, L. alexanderi Manhao (AY631880); 9, L. meyeri (LM16sRDNX); 10, L. kirschneri Grippotyphosa (JQ988856); 11, L. noguchii Panama CZ214K (AY631886); 12, L. santarosai Georgia LT117 (AY996805); 13, L. weilii Celledoni (AY631877); 14, L. borgpetersenii Hardjobovis (AM050569); 15, 30R; 16, AP33; 17, A-15; 18, M06; 19 , HS-7. 
고, $\operatorname{lipL} 32$ 는 $94^{\circ} \mathrm{C}$ 에서 5 분간 변성시킨 후 $94^{\circ} \mathrm{C}$ 에서 30 초 간 denaturation, $48^{\circ} \mathrm{C}$ 에서 30 초간 annealing, $72^{\circ} \mathrm{C}$ 에서 1 분 간 extension 순으로 35 회 증폭시켰으며, 최후 반응 $72^{\circ} \mathrm{C}$ 에서 3 분간 반응시켜 $\mathrm{PCR}$ 산물의 연장을 유도하였다. 각 반응마다 음성 대조군으로 template DNA 대신 증류수를 사용하였으며 교차오염을 예방하기 위하여 aerosol resistant tip을 사용하였다. 증폭산물은 Accuprep PCR purification kit (Bioneer, Daejeon, Korea)를 이용하여 정제 한 후 염기 서열을 분석하였다.

\section{렙토스피라 유전자 염기서열의 결정과 분석}

염기서열 분석은 (주) 제노텍(Daejeon, Korea)에 의뢰하 여 진행하였다. $16 \mathrm{~S} \mathrm{rDNA}$ 유전자 염기서열 분석을 위해 $27 \mathrm{~F}$ 와 518R 프라이머를 사용하였고, LipL32 유전자 염기 서열 분석을 위해서 LipL32F와 LipL32R 프라이머를 사 용하였다. 얻어진 염기서열은 MegAlign software package (DNASTAR, Lasergene 7.1, WI, USA)의 Clustal W를 이용
하여 GenBank database에서 얻은 참조 균주의 염기서열 과 비교 분석하였고, phylogenetic tree를 제작하였다. Tree 의 안정성을 조사하기 위해 bootstrap analysis (1,000회)를 수행하였다. 유사성에 대한 백분율은 MegAlign software 를 이용하여 결정하였다.

\section{염기서열의 accession number}

염기서열을 비교를 위해 사용된 염기서열들은 GenBank database (National Center for Biotechnology Information, $\mathrm{NCBI}$ )에서 얻었으며 참조로 사용한 렙토스피라 $16 \mathrm{~S}$ rDNA와 LipL 32 유전자 염기서열의 accession number는 Fig. 1,2와 Table 3,4에 표시하였다.

\section{RESULTS}

렙토스피라의 $16 \mathrm{~S} \mathrm{rDNA}$ 와 $\mathrm{LipL} 32$ 유전자를 타겟으로 하는 프라이머를 이용하여 $\mathrm{PCR}$ 을 수행한 결과, 15 개 모

Table 4. The similarity between partial lipL32 sequences of various reference Leptospira strains and isolates

\begin{tabular}{|c|c|c|c|c|c|c|c|c|c|c|c|c|c|c|c|c|}
\hline & 1 & 2 & 3 & 4 & 5 & 6 & 7 & 8 & 9 & 10 & 11 & 12 & 13 & 14 & 15 & 16 \\
\hline 1 & $* * *$ & 100 & 99.9 & 99.9 & 100 & 100 & 99.7 & 99.7 & 99.4 & 98.3 & 95.2 & 96.1 & 95.9 & 99.9 & 99.2 & 99.7 \\
\hline 2 & & $* * *$ & 99.9 & 99.9 & 100 & 100 & 99.7 & 99.7 & 99.4 & 98.3 & 95.2 & 96.1 & 95.9 & 99.9 & 99.2 & 99.7 \\
\hline 3 & & & $* * *$ & 100 & 99.9 & 99.9 & 99.6 & 99.6 & 99.3 & 98.5 & 95 & 96 & 95.7 & 100 & 99.3 & 99.6 \\
\hline 4 & & & & $* * *$ & 99.9 & 99.9 & 99.6 & 99.6 & 99.3 & 98.5 & 95 & 96 & 95.7 & 100 & 99.3 & 99.6 \\
\hline 5 & & & & & $* * *$ & 100 & 99.7 & 99.7 & 99.4 & 98.3 & 95.2 & 96.1 & 95.9 & 99.9 & 99.2 & 99.7 \\
\hline 6 & & & & & & $* * *$ & 99.7 & 99.7 & 99.4 & 98.3 & 95.2 & 96.1 & 95.9 & 99.9 & 99.2 & 99.7 \\
\hline 7 & & & & & & & $* * *$ & 99.7 & 99.4 & 98.3 & 95.2 & 96.1 & 95.9 & 99.6 & 98.9 & 99.7 \\
\hline 8 & & & & & & & & $* * *$ & 99.4 & 98.3 & 95.2 & 96.4 & 96.1 & 99.6 & 98.9 & 100 \\
\hline 9 & & & & & & & & & $* * *$ & 98.6 & 95.2 & 96.4 & 96.1 & 99.3 & 98.6 & 99.4 \\
\hline 10 & & & & & & & & & & $* * *$ & 94.5 & 95.6 & 95.5 & 98.5 & 97.8 & 98.3 \\
\hline 11 & & & & & & & & & & & $* * *$ & 96.3 & 96 & 95 & 94.4 & 95.2 \\
\hline 12 & & & & & & & & & & & & $* * *$ & 99.7 & 96 & 95.3 & 96.4 \\
\hline 13 & & & & & & & & & & & & & $* * *$ & 95.7 & 95 & 96.1 \\
\hline 14 & & & & & & & & & & & & & & $* * *$ & 99.3 & 99.6 \\
\hline 15 & & & & & & & & & & & & & & & $* * *$ & 98.9 \\
\hline 16 & & & & & & & & & & & & & & & & $* * *$ \\
\hline
\end{tabular}

1, partial lipL32 of $\boldsymbol{L}$. interrogans Lai (AY568679); 2, L. interrogans Autumnalis (JN210551); 3, L. interrogans 56601 (AY461908); 4 , L. interrogans Hardjoprajitno (AY461905); 5, L. interrogans Akiyami (AY461902); 6, L. interrogans RGA (AY461909); 7, L. interrogans Pomona RZ11 (AY461910); 8, L. interrogans Canicola RTCC 2824 (KC800990); 9, L. kirschneri 5621 (AY461917); 10, L. noguchii 1011 (AY461918); 11, L. santarosai HS-616 (AY461926); 12, L. weilii LT89-68 (AY461930); 13, L. borgpetersenii 1409 (AY461893); 14, 30R; 15, KH-1; 16, HS-7. 


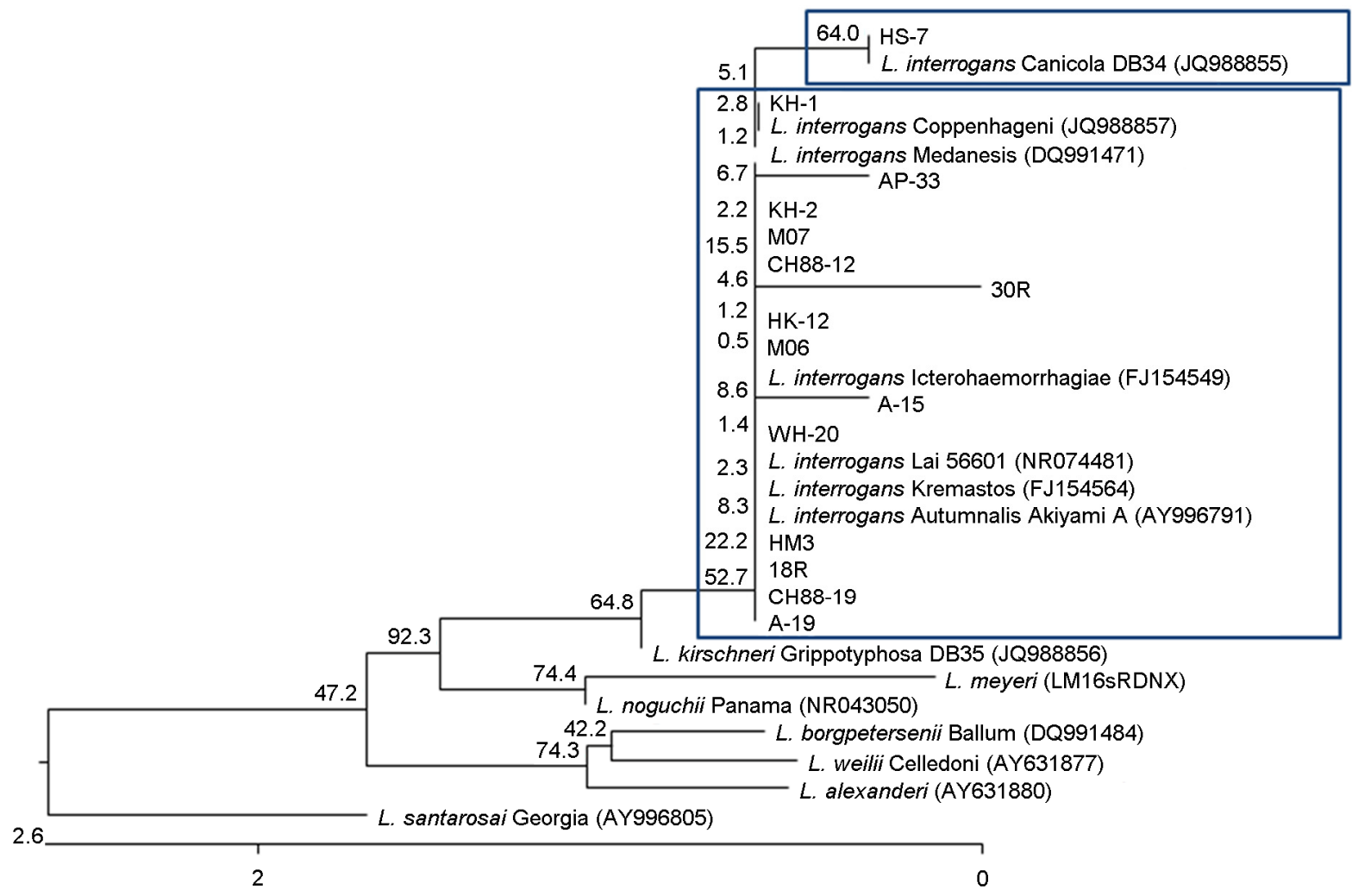

Figure 1. Dendrogram representing phylogenetic relationships between partial $16 \mathrm{~S}$ rDNA sequences (the size of about $323 \mathrm{bp}$ ) of reference Leptospira strains and $16 \mathrm{~S}$ rDNA PCR products of isolates. The phylogram was generated by neighbor-joining analysis with 1,000 bootstrapped replicates.

든 시료에서 각각 해당 유전자의 증폭을 확인하였다. $16 \mathrm{~S}$ $\mathrm{rDNA}$ 유전자를 타겟으로 $\mathrm{PCR}$ 을 수행한 시료에서 $529 \mathrm{bp}$ 크기의 증폭산물을 확인하였고, LipL32 유전자를 타겟으 로 한 시료에서는 $819 \mathrm{bp}$ 크기의 증폭산물을 확인하였다. 각 증폭산물을 정제하여 염기서열을 결정하였으며, 프라 이머를 포함한 양쪽 말단의 염기서열을 제거한 후 분석 하였다. 최종적으로 결정된 염기서열의 크기는 $16 \mathrm{~S} \mathrm{rDNA}$ 유전자는 $323 \mathrm{bp}, \mathrm{LipL} 32$ 유전자는 $727 \mathrm{bp}$ 였다. 이들 염 기서열과 GenBank database에서 얻은 다양한 렙토스피라 염기서열과 비교하였다. $16 \mathrm{~S} \mathrm{rDNA}$ 유전자 염기서열을 분 석한 결과, 국내 분리 균주 15 개 중 11 개 즉, $\mathrm{WH}-20,18 \mathrm{R}$, HM3, CH88-12, CH88-19, KH-1, KH-2, HK-12, A-19, M06, M07은 L. interrogans lai에 $100 \%$ 의 유사도를 나타내었 으며, 30R, A-15, AP33은 L. interrogans lai에 99.4 99.7\% 의 유사도를 나타내었다. 그리고 HS-7은 L. interrogans canicola에 $100 \%$ 의 유사도를 나타내었다. Table 3 에는 15 개 균주 중 대표적인 5 개 균주를 선별하여 참조 균주의
$16 \mathrm{~S} \mathrm{rDNA}$ 유전자 염기서열과의 유사도를 나타내었다. Genotype의 위치를 확인하기 위하여 균주들의 $16 \mathrm{~S} \mathrm{rDNA}$ 계통발생학적인 분석을 수행한 결과, HS-7는 L. interrogans canicola와 클러스터(Group 1)를 형성하였고, 나머지 균주 들은 L. interrogans lai와 클러스터(Group 2)를 형성하였다 (Fig. 1). LipL32 유전자 염기서열을 분석한 결과, 15 개 균 주 중 14개, 즉 $\mathrm{WH}-20,18 \mathrm{R}, 30 \mathrm{R}, \mathrm{HM} 3, \mathrm{AP} 33, \mathrm{CH} 88-12$, CH88-19, KH-1, KH-2, HK-12, A-15, A-19, M06, M07은 L. interrogans lai에 99.2 99.9\%의 유사도를 나타내었으며, 나머지 한 개는 L. interrogans canicola에 $100 \%$ 의 유사도 를 나타내었다. Table 4 에는 15 개 균주 중 대표적인 3 개 균주를 선별하여 참조 균주의 $\mathrm{LipL} 32$ 유전자 염기서열 과의 유사도를 나타내었다. Genotype의 위치를 확인하기 위하여 균주들의 LipL32 유전자의 계통발생학적인 분석 을 수행한 결과, 14 개 균주가 L. interrogans lai와 클러스 터(Group 1)를 형성하였고, HS-7은 L. interrogans canicola 와 클러스터(Group 2)를 형성하였다(Fig. 2). 


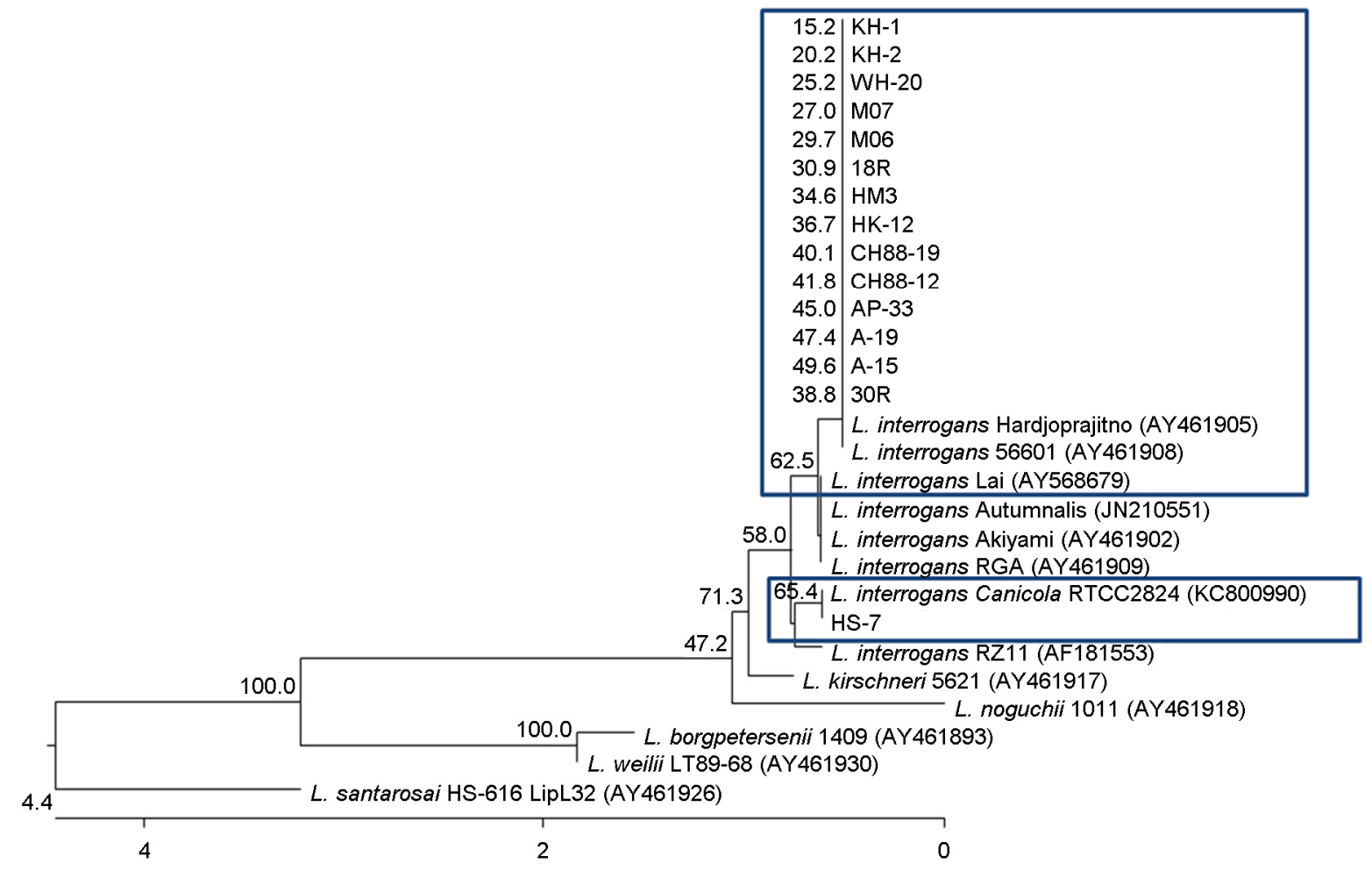

Figure 2. Dendrogram representing phylogenetic relationships between partial LipL 32 sequences (the size of about 727 bp) of reference Leptospira strains and LipL 32 PCR products of isolates. The phylogram was generated by neighbor-joining analysis with 1,000 bootstrapped replicates.

\section{DISCUSSION}

렙토스피라증은 L. interrogans sensu lato의 감염에 의해 발생되는 인수공통 감염병으로 발열, 두통, 근육통 등의 일반적인 증상을 보이고 심한 경우 내부장기출혈, 황달, 심부전 등의 증상을 나타낸다 (17). 우리나라에서 렙토 스피라증은 가을철 추수기에 농촌에서 많이 발생되어 1987년 제2종법종전염병으로 지정되었으며, 렙토스피라 의 주된 매개체는 Apodemus agrarius 등의 야생 설치류로 알려져 있다 (19). 렙토스피라를 감지하고 동정하기 위한 다양한 분자적인 방법이 개발되어 왔으며, $\mathrm{PCR}$ 을 기반으 로 한 전략은 여러 병원성 균의 진단에 유용하게 이용될 뿐만 아니라 새로운 종의 렙토스피라를 분류하기 위해서 도 사용되고 있다 (22). PCR을 이용한 렙토스피라 동정은 arbitrarily primed PCR (AP-PCR), low-stringency single specific primer PCR (LSSP-PCR), PCR restriction endonuclease analysis (PCR-REA), specific probes 그리고 real-time quantitative PCR
방법 등으로 수행되었다 $(19,23) . \mathrm{PCR}$ 기법을 이용해서 렙토스피라증의 조기진단이 가능하고, 렙토스피라의 혈청 형이나 종의 분류도 가능하다는 것이 알려졌다 (24). 다 양한 임상시료로부터 렙토스피라의 종을 감지하기 위해 서 이 기법이 사용되고 있고, 또한 렙토스피라의 종 분류 는 이런 유전적인 방법을 통해 보다 확실해지고 있다 $(10,20,25,26)$. 본 연구에서 렙토스피라 동정을 위해 $16 \mathrm{~S} \mathrm{rDNA}$ 와 lipL32 유전자를 선택하였다. $16 \mathrm{~S} \mathrm{rDNA}$ 유 전자의 염기서열 분석은 미지의 세균 확인 및 동정에 포 괄적으로 이용되고, 세균의 분류목적으로 흔하게 이용된 다 $(12,15)$. 또한 렙토스피라의 $16 \mathrm{~S} \mathrm{rDNA}$ 부분 염기서열 은 많이 알려져 있어 종의 동정에 유용한 유전자로 사용 할 수 있다 (12). LipL32 단백은 바깥 쪽 막 표면에 노출 된 단백으로서 세포에서 가장 풍부한 단백질이며 배양 중이나 감염 중 생체 내에서 발현되고, 많은 렙토스피라 균주들의 LipL32 유전자서열이 결정되어 있어 이 유전자 를 이용한 렙토스피라의 분류 및 동정이 많이 시도되고 있다 $(14,16,22)$. 
본 연구에서는 PCR 기법과 염기서열 분석을 이용하여 15 개의 국내 분리주를 동정하고자 하였다. 이 균주들은 과거 혈청학적인 방법으로 분류된 균주들로서 WH-20, $\mathrm{KH}-1, \mathrm{KH}-2, \mathrm{~A}-15, \mathrm{~A}-19, \mathrm{M} 06, \mathrm{M} 07$ 은 L. interrogans 혈청 형 lai로 동정되었고, HS-7 균주는 L. interrogans 혈청형 canicola로 동정되었었다. 다른 7 개 균주, 즉 $18 \mathrm{R}$ 과 $30 \mathrm{R}$, AP33, HM3, CH88-12, CH88-19, HK12 렙토스피라 분리주 들은 혈청학적으로 분류가 어려워서 연구자들간의 많은 논란이 있었는데, 이 중 $18 \mathrm{R}$ 과 $\mathrm{HM} 3$ 는 기존의 혈청형과 구별되어 혈청형 hongchon과 yeonchon으로 명명된 바 있 다. 또한, AP-33은 국내 분리주 WH-20와 같은 혈청형 lai 로 동정되었고, 이외의 균주들은 새로운 혈청형임을 시 사하는 보고가 있었다 $(8,10,18,27)$.

본 연구를 통해 국내 분리주 15 개를 분자생물학적으로 재분류하였으며, 이 중 HS-7은 분자생물학적 L. interrogans canicola로 분류되었고, 다른 14 개 균주들은 모두 $L$. interrogans lai로 분류되었다. Genospecies L. interrogans에 는 다양한 혈청형, 즉 icterohaemorrhagiae, lai, copenhageni, canicola, pomona, saxkoebing, wolffi, pyrogenes, autumnalis, bataviae 등의 혈청형이 포함된다 (10). 따라서 국내에 서 분리된 균주들은 과거 혈청학적으로 lai, hongchon, yeonchon, canicola 등으로 분류되었었지만, 분자생물학적 으로는 모두 L. interrogans에 속하는 것으로 나타났다.

다른 genospecies인 L. kirschneri에도 다양한 혈청형 (bogvere, bulgarica, butembo, cynopteri, dakota, dania, grippotyphosa, kabura, kambale, mwogolo, ndambari, ndahambukuje, ramisi, sokoine 그리고 tsaratsovo)이 포함 된다 $(10,25)$. 위의 15 개 균주 외에 렙토스피라 분리균 $\mathrm{AP} 31$ 의 유전자를 추가로 분석하였다. AP31 균주는 서로 다른 실험실에서 각각 유지 보관되었던 같은 이름의 두 균주를 사용하였다. 한 균주의 $16 \mathrm{~S} \mathrm{rDNA}$ 와 LipL32 유전 자는 L. kirschneri와 $100 \%$ 유사도를 나타낸 반면, 다른 한 균주의 $16 \mathrm{~s} \mathrm{rDNA}$ 와 LipL32 유전자는 L. interrogans lai와 $99.9 \%$ 유사도를 나타낸 것을 확인하였다 (data not shown). 렙토스피라는 균주의 특성상 냉동 혹은 동결보존이 어렵 고 지속적으로 계대배양을 해야 하기 때문에 계속 계대 배양되고 있는 2 개 이상의 균종의 우연한 혼합배양의 결 과 또는 labeling 잘 못 등의 결과로 균종이 바꿜 가능성 이 있다 (28). 이와 같은 원인으로 인해 서로 다른 실험실 에서 오랜 기간 유지되어 온 동일한 분리 균주가 각각 다른 특성을 나타낼 수 있을 것으로 사료된다. 따라서 우
리나라에 genospecies L. interrogans 외에도 L. kirschneri에 속한 균주가 존재함을 배제할 수 없다.

본 연구에서는 최초로 국내 렙토스피라 분리 균주 중 일부를 분자생물학적으로 분류해 보았다. 렙토스피라는 진단 및 백신제조 등을 위해서 균의 동정이 필수적이라 할 수 있다. 과거에는 혈청학적인 진단법과 동정법이 주 로 사용되었지만, 분자생물학적인 진단법의 적용 및 관련 역학조사를 위해서 국내에서 분리된 다양한 균주들을 대 상으로 한 분자생물학적 접근의 후속연구가 필요할 것으 로 사료된다.

\section{REFERENCES}

1) Yim EK, Kim YW, Lee JS, Chang IA, Baek LJ, Song JW, et $a l$. Detection of leptospiral DNA from field rodents by PCR. J Bacteriol Virol 2003;33:177-81.

2) Bharti AR, Nally JE, Ricaldi JN, Matthias MA, Diaz MM, Lovett MA, et al. Leptospirosis: a zoonotic disease of global importance. Lancet Infect Dis 2003;3:757-71.

3) Kim MJ. Leptospirosis in the Republic of Korea: Historical Perspectives, Current Status and Future Challenges. Infect Chemother 2013;45:137-44.

4) Adler B, de la Peña Moctezuma A. Leptospira and leptospirosis. Vet Microbiol 2010;27:287-96.

5) Evangelista KV, Coburn J. Leptospira as an emerging pathogen: a review of its biology, pathogenesis and host immune responses. Future Microbiol 2010;5:1413-25.

6) Chang WH, Kim YW, Oh HB, Cho MK, Kee SH, Kim HJ. Serovar identification and genetic characterization of Leptospira isolates by arbitrarily primed PCR and ribotyping. J Korean Soc Microbiol 1999;34:409-21.

7) Cerqueira GM, Picardeau M. A century of Leptospira strain typing. Infect Genet Evol 2009;9:760-8.

8) Levett PN. Leptospirosis. Clin Microbiol Rev 2001;14:296326.

9) Oh HB, Chang WH, Cho MK, Seong WK, Park KS. Identification of new serovar yeonchon and hongchon belonging to Leptospira interrogans Icterohaemorrhagiae serogroup. J Kor Soc Microbiol 1991;26:253-62.

10) Ramadass P, Jarvis BD, Corner RJ, Penny D, Marshall RB. Genetic characterization of pathogenic Leptospira species by DNA hybridization. Int J Syst Bacteriol 1992;42:215-9.

11) Turk N, Milas Z, Mojcec V, Ruzic-Sabljic E, Staresina V, 
Stritof Z, et al. Molecular analysis of Leptospira spp. isolated from humans by restriction fragment length polymorphism, real-time PCR and pulsed-field gel electrophoresis. FEMS Microbiol Lett 2009;300:174-9.

12) Morey RE, Galloway RL, Bragg SL, Steigerwalt AG, Mayer LW, Levett PN. Species-specific identification of Leptospiraceae by $16 \mathrm{~S}$ rRNA gene sequencing. J Clin Microbiol 2006;44:3510-6.

13) La Scola B, Bui LT, Baranton G, Khamis A, Raoult D. Partial rpoB gene sequencing for identification of Leptospira species. FEMS Microbiol Lett 2006;263:142-7.

14) Thaipadungpanit J, Chierakul W, Wuthiekanun V, Limmathurotsakul D, Amornchai $\mathrm{P}$, Boonslip S, et al. Diagnostic accuracy of real-time PCR assays targeting 16S rRNA and lipL32 genes for human leptospirosis in Thailand: a case-control study. PLoS One 2011;6:e16236.

15) Clarridge JE 3rd. Impact of 16S rRNA gene sequence analysis for identification of bacteria on clinical microbiology and infectious diseases. Clin Microbiol Rev 2004;17:840-62.

16) Boonyod D, Poovorawan Y, Bhattarakosol P, Chirathaworn C. LipL32, an outer membrane protein of Leptospira, as an antigen in a dipstick assay for diagnosis of leptospirosis. Asian Pac J Allergy Immunol 2005;23:133-41.

17) Faine S. Guidelines for the control of leptospirosis. WHO. 1982.

18) Lane DJ, Pace B, Olsen GJ, Stahl DA, Sogin ML, Pace NR. Rapid determination of 16S rRNA sequences for phylogenetic analyses. Proc Natl Acad Sci U S A 1985;82:6955-9.

19) Cho MK, Kee SH, Song HJ, Kim KH, Song KJ, Baek LJ, et al. Infection rate of Leptospira interrogans in the field rodent, Apodemus agrarius, in Korea. Epidemiol Infect 1998;3:685 -90 .

20) Wuyts J, Van de Peer Y, Winkelmans T, De Wachter R. The
European database on small subunit rRNA. Nucleic Acids Res 2002;30:183-5.

21) Haake DA, Suchard MA, Kelley MM, Dundoo M, Alt DP, Zuerner RL. Molecular evolution and mosaicism of leptospiral outer membrane proteins involves horizontal DNA transfer. J Bacteriol 2004;186:2818-28

22) Haake DA, Chao G, Zuerner RL, Barnett JK, Barnett D, Mazel $\mathrm{M}$, et al. The leptospiral major outer membrane protein LipL32 is a lipoprotein expressed during mammalian infection. Infect Immun 2000;68:2276-85.

23) Shang ES, Summers TA, Haake DA. Molecular cloning and sequence analysis of the gene encoding LipL41, a surfaceexposed lipoprotein of pathogenic Leptospira species. Infect Immun 1996;64:2322-30.

24) Perez J, Goarant C. Rapid Leptospira identification by direct sequencing of the diagnostic PCR products in New Caledonia. BMC Microbiol 2010;10:325.

25) Mgode GF, Machang'u RS, Goris MG, Engelbert M, Sondij S, Hartskeerl RA. New Leptospira serovar sokoine of serogroup Icterohaemorrhagiae from cattle in Tanzania. Int J Syst Evol Microbiol 2006;56:593-7.

26) Yasuda PH, Steigerwalt AG, Sulzer KR, Kaufmann AF, Rogers F, Brenner DJ. Deoxyribonucleic acid relatedness between serogroups and serovars in the family Leptospiraceae with proposals for seven new Leptospira species. Int J Syst Evol Microbiol 1987;37:407-15.

27) Chang WH, Kee SH, Park KH, Kim SY, Kim IS, Choi MS. Antigenic analysis of Leptospira interrogans isolated in Korea using monoclonal antibodies and cross-agglutinin absorption test. J Kor Soc Microbiol 1989;24:165-73.

28) Park KH, Chang WH. Serovar identification of leptospiral strain HS-7 isolated in Korea by monoclonal antibodies. J Kor Soc Microbiol 1988;23:293-305. 